\title{
Emission sources of atmospheric phosphine and simulation of phosphine formation
}

\author{
CAO Haifeng (曹海峰) ${ }^{1}$, LIU Ji'ang (刘季昂 $)^{1}$, ZHUANG Yahui (庄亚辉) ${ }^{1}$ \\ \& Dietmar Glindemann ${ }^{2}$
}

1. Research Center for Eco-environmental Sciences, Chinese Academy of Sciences, Beijing 100085, China;

2. Department of Chemistry, University of British Columbia, Vancouver, BC, V6T 1Z1, Canada

Correspondence should be addressed to Cao Haifeng (email: htcao@263.net)

Received September 3, 1999

\begin{abstract}
Preliminary results on the emission sources of atmospheric phosphine and the types of its precursors in the environment are described. Sunlight plays a more important role than oxygen in its degradation. The vertical profile of phosphine levels in ambient air has been measured. Laboratory simulation of phosphine formation under anaerobic conditions shows that addition of chicken manure, bone powder, or lecithin leads to an increment in phosphine emission. Phosphine can also be adsorbed to soil matrix and thus can survive in soil and sediment. Adsorption and light degradation explain the low ambient levels of phosphine.
\end{abstract}

Keywords phosphine, atmosphere, soil, sediment, emission source, precursor, anaerobic biological process.

The occurrence of phosphine in the natural environment, as well as the role of phosphine in the biogeochemical cycling of phosphorus, has been disputed for nearly half a century. In 1959, Tssubota $^{[1]}$ failed to get convincing evidence of phosphine formation in paddy rice fields because of the primitivity of this analytical phosphine technique. Devai ${ }^{[2]}$ succeeded in discovering phosphine in volatile compounds of sewage plants. Since 1993, the enrichment and analytical techniques for ambient phosphine have become mature. Several papers appeared on the "matrix-bound" phosphine contained in anaerobic sediments, sludge and soils, as well as phosphine emissions from waste digestion, animal manure, marsh gas, and landfill sites ${ }^{[3-7]}$. Glindemann ${ }^{[8]}$ detected the existence of phosphine in the atmosphere. He also tackled the formation mecha$\operatorname{nism}^{[9]}$.

Liu et al. ${ }^{1)}$ detected phosphine in sediment samples and in ambient air adjacent to a paddy field near Beijing, challenging the previous unsuccessful attempts to identify phosphine in paddy field emissions. China, as a predominantly agricultural country with large areas of paddy fields, and numerous eutrophic lakes and reservoirs as well, is a favorite place for studying the natural gaseous phosphorus emissions. The ambient levels of phosphine in Beijing are relatively high, as compared with those in Germany and South America. This implies hitherto unknown but impor-

1) Liu, J. A., Cao, H. F., Zhuang, Y. H. et al., Environmental analysis of phosphine in a paddy field and from other places during summer temperate climate in Beijing, China, Water, Air \& Soil Pollution, (in press). 
tant phosphorus cycling processes, which might have both positive and negative effects on the biomass growth in Chinese fields and forests by a general phosphorus limitation. Since phosphine is an intermediate of anaerobic processes in soil, its subsequent oxidation to phosphoric acid serves as an activation process of soil phosphorus originally unavailable to plants. This is an overlooked positive aspect of phosphine on plant growth. Phosphine is also a reactive atmospheric trace gas, which competes with methane and other greenhouse gases for hydroxyl radicals, and thus enhances an indirect greenhouse effect (the so-called coupling effect ${ }^{[10]}$ ). Phosphine itself is a toxic substance, which inhibits the growth of soil microorganisms and damages crop roots. These toxic effects would not only influence the emissions fluxes of other greenhouse gases from soil, but also could cause disturbance in the rhizosphere.

Very few publications have been devoted to phosphine formation mechanisms in the environment. More work has to be done to clarify the biogenic phosphine formation. In this paper, we simulate the conversion of typical phosphorus-containing substrates into phosphine under anaerobic conditions.

\section{Material and methods}

\subsection{Instrument}

A Hewlett-Packard gas chromatograph of Model HP-5890A equipped with a thermo-ionic nitrogen/phosphorus detector (NPD) and a PLOT $\mathrm{Al}_{2} \mathrm{O}_{3} / \mathrm{Na}_{2} \mathrm{SO}_{4}$ capillary column $(25 \mathrm{~m} \times 0.53 \mathrm{~mm}$ $\times 10 \mu \mathrm{m}$ ) was employed for all phosphine determinations. Around 10-100 $\mathrm{ml}$ of gas samples were cryotrapped to reach a detection limit for phosphine of $0.1 \mathrm{ng} \cdot \mathrm{m}^{-3}$.

\subsection{Reagents and materials}

A certified technical phosphine gas standard of $987 \mathrm{ppm}(\mathrm{v} / \mathrm{v})$ phosphine in nitrogen (Helium-Beijing Analytical Gas Industrial Co., Ltd.) served for quantification. Soybean lecithin (Beijing Microbe Culture Media, phosphorus content 2\%-2.5\%), peptone (Beijing Red Star Biochemicals, Inc.), disodium salt of uridine-5' -monophosphate (Shanghai Biochemical Institute, content $>90 \%$ ) and disodium salt of creatine- $5^{\prime}$-monophosphate (Shanghai Reagent Co., content $>97 \%$ ) are all of biochemical grade. Potassium dihydrogen phosphate (Beijing Red Star Chemicals, Inc.) is of analytical grade. Animal bone powder and chicken faeces were dried before use.

\subsection{Sampling and anaerobic incubation}

Three parallel ambient samples together with one control sample of $100 \mathrm{ml}$ were taken for each occasion and location. Plastic sampling syringes were employed.

For anaerobic incubation experiments, sediment (upper layer $0-25 \mathrm{~cm}$ ) was taken from a local sewage channel. After sorting out the coarse and bulky matter, the sediment was stirred thoroughly. About $40 \mathrm{~g}$ aliquots of this sediment were weighed and added to glass vials (120 ml) together with $50 \mathrm{ml}$ water and weighed amounts of phosphorus-containing substrates (either pure 
chemicals or materials). The vials were then purged with high-purity nitrogen for 5 minutes, and were stopped with septa. For each substrate studied, three or five samples plus two controls were run in parallel. Then the sealed vials were incubated on a thermostated shaker at $30^{\circ} \mathrm{C} \pm 1^{\circ} \mathrm{C}$ with a dark cover. The shaker has a speed of $90 \mathrm{r} / \mathrm{min}$. The head-space gas samples were taken with the aid of two $50 \mathrm{ml}$ plastic syringes. High-purity nitrogen in one syringe with a long needle $(10 \mathrm{~cm})$ was injected through the sediment into the vial, while the other empty syringe with a short needle $(2 \mathrm{~cm})$ was used to take head-space gas from the same bottle. The gas samples as well as phosphine liberated from matrix-bound samples were subjected to GC analysis, as described elsewhere $^{[5]}$.

\section{Results and discussions}

\subsection{Effect of sunlight on ambient levels of phosphine}

Our previous field study in Beijing ${ }^{[10]}$ showed that sunlight has a definite effect on the ambient phosphine concentrations. The phosphine degradation mechanism can probably be a photochemical elimination reaction typical of reducing gases. Under the induction of ultra-violet radiation, atmospheric ozone molecules are photolyzed to form hydroxyl radicals, which break the P-H bonds in phosphine molecules. Despite of its relatively short average life span in the atmosphere, phosphine can survive in the nighttime and in heavily clouded daytime. Consequently, phosphine serves as a phosphorus carrier through the atmosphere in the phosphorus cycling.

As shown in fig. 1, experimental simulation in Tedlar gas bags indicated that oxidation of phosphine by air in darkness is slow, while light-induced rapid degradation of phosphine occurs even in the absence of air. The fastest degradation of phosphine occurred in the presence of both air and sunlight. It is therefore clear, that the spontaneous oxidation of phosphine in the atmosphere is not too fast, and that the elimination of phosphine in the atmosphere is closely related to sunlight radiation.

\subsection{Spatial distribution of phosphine}

It is interesting to know the vertical profile of phosphine. Samples were taken at each $50 \mathrm{~m}$ height of a meteorological tower $300 \mathrm{~m}$ tall at the Institute of Atmospheric Physics, Beijing. The sampling time is around 7:30 am in spring. The results are shown in Fig. 2. Phosphine was observed at all heights monitored early in the morning. No significant fluctuation in phosphine levels with height was observed. At noon with no cloud cover, phosphine can no longer be detected. It is decomposed and completes a cycling process by deposition to the ground.

\subsection{Correlation between phosphine formation and microbial activity}

It was thought that phosphine can be formed as a reduction product of phosphate compounds. However, the mechanism of phosphine formation is not clear. It is likely a microbial process under anaerobic conditions. We used soybean lecithin as a substrate, and sterilized both the substrate and sediment under $120^{\circ} \mathrm{C}$ for $30 \mathrm{~min}$. After five days of anaerobic incubation, the head-space gas 


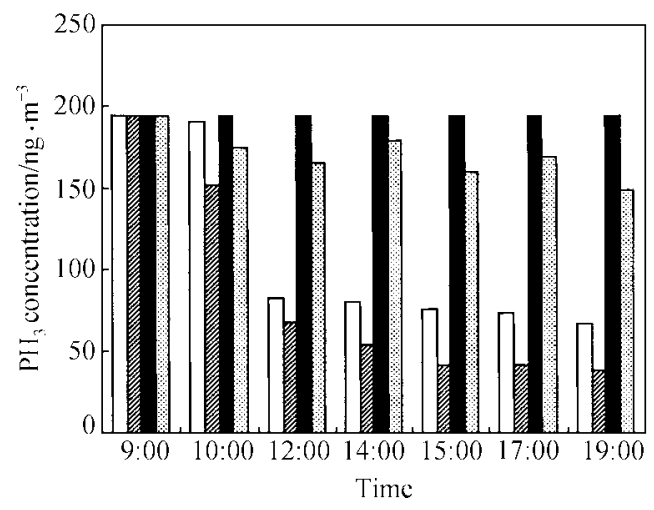

Fig. 1. Phosphine degradation in plastic bags. $\square, \mathrm{N}_{2}$,light; $\square$, air, light; $\mathbf{\square}, \mathrm{N}_{2} ; \square$, air.

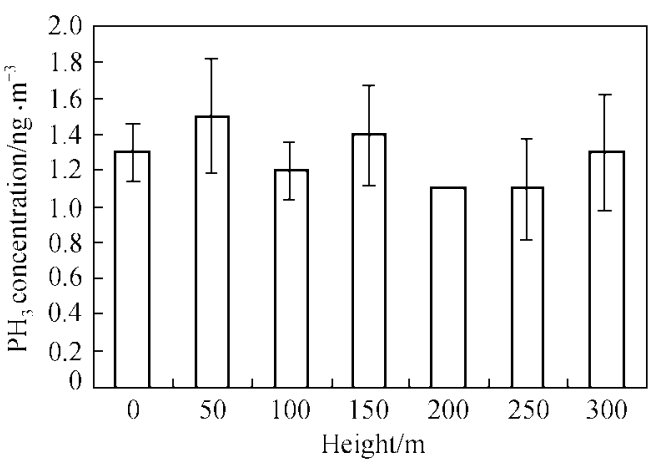

Fig. 2. Spatial distribution of phosphine.

was analyzed for phosphine. As is evident in table 1, the amount of phosphine in the top space of the sterilized lecithin vial is much lower than the non-sterilized sample, showing the important role of microbes played in phosphine formation. Nevertheless, phosphine can still be detected in sterilized lecithin samples. The minute amount of phosphine detected in sterilized samples stems probably from the residual phosphine formed in the sediment prior to sterilization. Phosphine formation is likely related to microbial activities in soil.

Table 1 Comparison of phosphine formation in sterilized and non-sterilized lecithin samples

(Dosage of lecithin in sediment: $0.115 \mathrm{mg} \mathrm{P} \cdot \mathrm{g}^{-1}$ )

\begin{tabular}{cccc}
\hline $\mathrm{PH}_{3}$ in head space & Non-sterilized sample & Sterilized sample & Sterilized control \\
\hline $\mathrm{PH}_{3}\left({\left.\mathrm{pg} \mathrm{P} \bullet \mathrm{kg}^{-1}\right)}^{-1}\right.$ & 8.8 & 1.2 & 2.0 \\
\hline
\end{tabular}

\subsection{Preliminary study of phosphine precursors}

Two typical phosphorus-containing biogenic materials have been selected as substrates. One is animal bone powder, and the other is sterilized and dried chicken faeces. The phosphorus contents of these materials are shown in table 2. The dosages of these two materials added in the tests were 1.404 and $0.337 \mathrm{mg}$ phosphorus per gram of the dried sediment, respectively. Head-space gas samples were taken for analysis. The analytical results are shown in fig. 3 . The data were subjected to a two-factor statistical variance analysis. The two factors in question are the amount of substrate added and time. Significant difference in top-space phosphine concentrations was observed between controls and substrates, as shown in table 3. Addition of phosphorus-containing materials into the sediment samples did enhance phosphine emission, especially in the case of bone powder. This might be explained by the higher phosphorus content in bone powder.

Table 2 Phosphorus contents in bone powder and chicken faeces

\begin{tabular}{ccccc}
\hline \multicolumn{1}{c}{ Material } & $\begin{array}{c}\text { Total phosphorus } \\
\text { (as P) }\end{array}$ & $\begin{array}{c}\text { Organic phosphorus } \\
\text { (as P) }\end{array}$ & Organic P/total & $\begin{array}{c}\text { Soluble phosphorus } \\
\text { (as P) }\end{array}$ \\
\hline Bone powder & $14.04 \%$ & $4.39 \%$ & $31.27 \%$ & $0.08 \%$ \\
Chicken faeces & $7.72 \%$ & $0.54 \%$ & $16.02 \%$ & $2.10 \%$ \\
\hline
\end{tabular}

2.5 Inorganic phosphate as a potential precursor of phosphine

Potassium dihydrogen phosphate was tested as a potential precursor of phosphine. The dos- 
age of potassium dihydrogen phosphate was $0.0057-0.228 \mathrm{mg} \mathrm{P}$ per gram of dried sediment. Within the whole incubation period of $8 \mathrm{~d}$, no statistically significant difference in phosphine emission was observed as compared with the control runs (fig. 4).

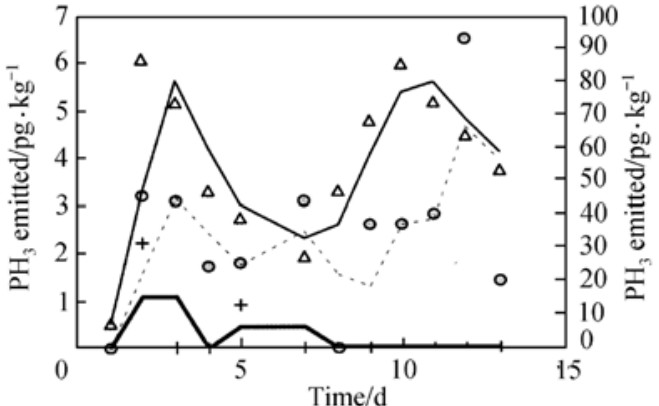

Fig. 3. Phosphine emission from substrates of bone power and chicken faeces. +; Control; $\bigcirc$; Chicken faeces; $\triangle$, bone powder; _—, control; - . - - , Chicken faeces; —_, Bone powder.

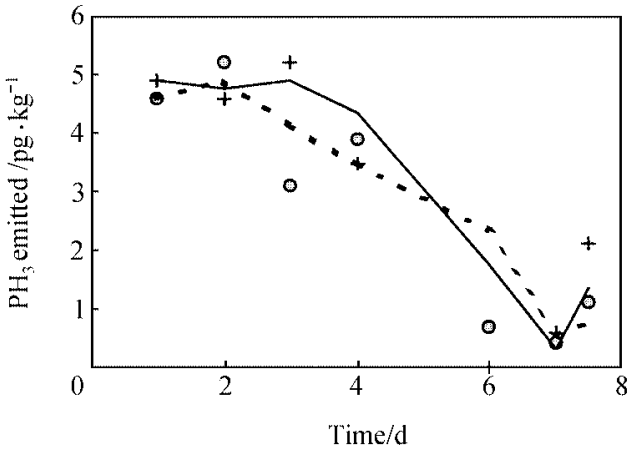

Fig. 4. Phosphine emission from a substrate of potassium dihydrogen phosphate. +, Control; $\mathrm{O}, \mathrm{KH}_{2} \mathrm{PO}_{4} ;-$, Control; - - - -, $\mathrm{KH}_{2} \mathrm{PO}_{4}$.

Table 3 Statistical significance between substrate samples and controls (two-factor variance analysis)

\begin{tabular}{ccc}
\hline Variance source & $F$ value & Critical value $\left(F_{\alpha=0.05}\right)$ \\
\hline Chicken faeces & 17.90 & 4.84 \\
Time & 1.14 & 2.82 \\
Bone powder & 66.53 & 4.84 \\
Time & 1.03 & 2.82 \\
\hline
\end{tabular}

Devai et al. ${ }^{[7]}$ have studied the same system, and claimed that the quantity of phosphine increased with an increment in potassium dihydrogen phosphate added to the system. However, they did not report the performance of control runs. It would be difficult to judge whether the phosphine comes from the substrate. Nevertheless, they mentioneds that the addition of peptone into the culture fluid improved the microbial activity. In our experiments, we added peptone too. Our experiments, however, lasted only $8 \mathrm{~d}$, and are too short to draw any conclusion. Experiments with longer periods will be performed later.

\subsection{Phosphate esters as potential precursors of phosphine}

Most of the natural organic compounds of phosphorus are phosphate esters containing $\mathrm{C}-\mathrm{O}-\mathrm{P}$ bonds. Here we present the results of a few natural phosphate esters as substrates. The dosages of disodium salt of uridine-5'- monophosphate, disodium salt of creatine-5'- monophosphate and soybean lecithin are $0.0842 \mathrm{mg} \mathrm{P} \cdot \mathrm{g}^{-1}, 0.0948 \mathrm{mg} \mathrm{P} \cdot \mathrm{g}^{-1}$ and $0.115 \mathrm{mg} \mathrm{P} \cdot \mathrm{g}^{-1}$, respectively. In all culture fluids, peptone (30 or $400 \mathrm{mg}$ ) was added. For uridine phosphate and creatine phosphate, no statistically significant difference was found as compared with controls. Within the incubation period, we observed significant discrepancy only between the lecithin and control samples (fig. 5). 
The data were then subjected to the statistical variance analysis. In the case of $30 \mathrm{mg}$ of peptone added, its $F$ value 8.84 is larger than the critical value of the correlation coefficient 5.99 at $\alpha=0.05$. This implies significant release of phosphine from lecithin culture over the control. Similar conclusion can be drawn for fig. 5, where $400 \mathrm{mg}$ of peptone has been employed to improve Here its $F$ value 53.70 is much greater than the critical value 5.99 at $\alpha=0.05$.

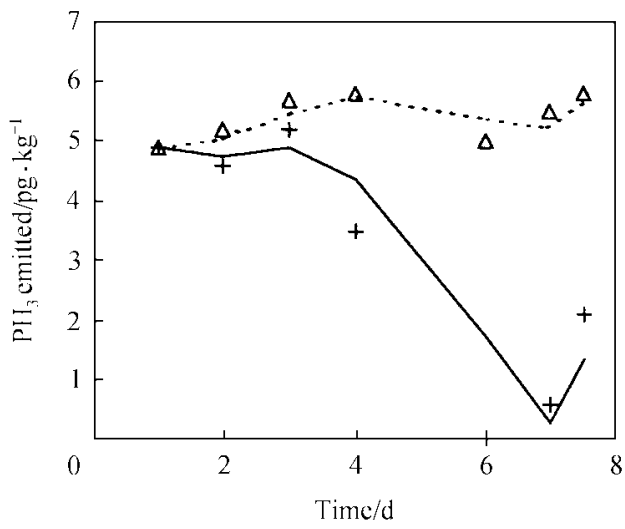

2.7 Effects of substrates on matrix-bound Fig. 5. Phosphine emission from a substrate of lecithin. phosphine

+, Control; $\triangle$, lecithin; —-, control; -----, 10 cithin.

In our above experiments, we measured only the phosphine accumulated in the head space of vials. However, it is known that phosphine is also matrix-bound to sediment particles. This might result from back donation bond formation between phosphine molecules and transition metal ions in soil. Hence soil is also a pool of phosphine. Evidently, emission of phosphine into the atmosphere consists of a series of slow processes: its desorption from soil particles, its diffusion through the soil and/or water layers, and its dispersion into ambient air.

We measured matrix-bound phosphine as indicated in fig. 6. In this case, potassium dihydrogen phosphate was employed as substrate $\left(0.115 \mathrm{mg} \mathrm{P} \cdot \mathrm{g}^{-1}\right)$, and peptone as promoter $(400 \mathrm{mg})$. Fig. 6 shows that more matrix-bound phosphine was found in substrate- added samples than in control samples. Again variance analysis gave significant results. Its $F$ value 52.36 is greater than

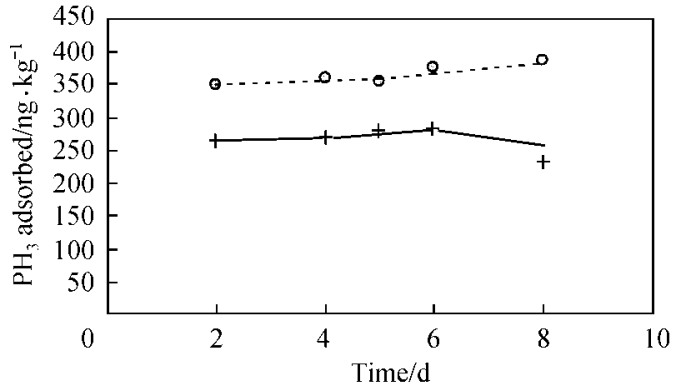

Fig. 6. +, Control; $\mathrm{O}, \mathrm{KH}_{2} \mathrm{PO}_{4}$; - - , control; - - - -, $\mathrm{KH}_{2} \mathrm{PO}_{4}$. the critical value 7.71 at $\alpha=0.05$, implying that phosphine is formed and accumulated in the sediment during anaerobic incubation. Only a minute fraction of phosphine was released into ambient air.

All the pure phosphorus-containing compounds gave less phosphine emission than bone powder and chicken faeces. This might imply that bone and faeces contain types of phosporus-containing compounds other than those we employed in this work. Bone and faeces serve as good substrates for phosphine formation.

\section{Conclusions}

(1) Light irradiation plays an important role in rapid elimination of phosphine in the atmos- 
phere. Phosphine acts as a carrier of phosphorus through the atmosphere in phosphorus cycling.

(2) Bone powder and chicken faeces caused an increment in phosphine emissions. Under anaerobic conditions, phosphorus in organic materials can be converted into phosphine.

(3) Within short incubation periods of $8-15 \mathrm{~d}$, it is still too early to draw conclusions on the transformation of inorganic phosphates into phosphine. Follow-up experiments with longer incubation time will be done.

(4) Matrix-bound phosphine in sediments serves as a pool of phosphorus. The actual amount of phosphine released into ambient air is much less than the total amount of phosphine formed in sediments.

Acknowledgments We appreciate the support of Ms. Yizhong Wang and Mr. Wenzhi Song in incubation experiments and field survey. We thank Prof. G. Gassmann for providing GC accessories. This work was supported by the National Natural Science Foundation of China (Grant No. 39790100)

\section{References}

1. Tssubota, G., Phosphate reduction in the paddy field, Soil \& Plant Food (Tokyo), 1959, 5: 10.

2. Devai, I., Felfoldy, L., Wintter, I., et al., Detection of phosphine: new aspects of the phosphorus cycle in the hydro-sphere, Nature, 1988, 333: 343.

3. Gassmann, G., Schorn, F., Phosphine from harbor surface sediment, Naturwissenschaften, 1993, 80: 78.

4. Gassmann, G., Phosphine in fluvial and marine hydrosphere, Mar. Chem., 1994, 45: 197.

5. Glindemann, D., Bergmann, A., Spontaneous emission of phosphine from animals slurry treatment processing, Zbl. Hyg., 1995, 198: 49.

6. Glindemann, D., Stotmeister, U., Bergmann, A., Free phosphine from the anaerobic biosphere, Environ. Sci. \& Pollu. Res., 1996, 3: 17 .

7. Devai, I., Delaune, R. D., Evidence for phosphine production and emission from Louisiana and Florida marsh soils, Org. Geochem., 1995, 23: 277.

8. Glindemann, D., Bergmann, A., Phosphine in the lower terrestrial troposphere, Naturwissenschaften, 1996, 83: 131.

9. Eismann, F, Glindemann, D, Bergmann, A. et al., Soil as source and sink of phosphine, Chemosphere, 1997, $35: 523$.

10. Prinn, R. G., The interactive atmosphere: global atmospheric-biospheric chemistry, Ambio., 1994, $23: 50$. 